\title{
From ear to uncertainty: vestibular contributions to cognitive function
}

\section{Paul F. Smith* and Yiwen Zheng}

Department Pharmacology and Toxicology, School of Medical Sciences, and the Brain Health Research Centre, University of Otago, Dunedin, New Zealand

\section{Edited by:}

Stephane Besnard, INSERM U1075,

France

\section{Reviewed by:}

Alberto E. Pereda, Albert Einstein

College of Medicine of Yeshiva

University, USA

Stephane Besnard, INSERM U1075,

France

\section{*Correspondence:}

Paul F. Smith, Department

Pharmacology and Toxicology,

School of Medical Sciences, and the

Brain Health Research Centre,

University of Otago, Frederick St., 9045, Dunedin, New Zealand

e-mail:paul.smith@

stonebow.otago.ac.nz
In addition to the deficits in the vestibulo-ocular and vestibulo-spinal reflexes that occur following vestibular dysfunction, there is substantial evidence that vestibular loss also causes cognitive disorders, some of which may be due to the reflexive deficits and some of which are related to the role that ascending vestibular pathways to the limbic system and neocortex play in spatial orientation. In this review we summarize the evidence that vestibular loss causes cognitive disorders, especially spatial memory deficits, in animals and humans and critically evaluate the evidence that these deficits are not due to hearing loss, problems with motor control, oscillopsia or anxiety and depression. We review the evidence that vestibular lesions affect head direction and place cells as well as the emerging evidence that artificial activation of the vestibular system, using galvanic vestibular stimulation (GVS), can modulate cognitive function.

Keywords: vestibular, spatial memory, cognition, hippocampus, vestibular lesions

\section{INTRODUCTION}

Recent epidemiological studies have demonstrated that vestibular disorders occur in more than $35 \%$ of adults aged 40 or older; between the ages of 60 and 69 , the prevalence increases to almost $50 \%$ and between 70 and 79, it is 69\% (Agrawal et al., 2009). Saber Tehrani et al. (2013) has estimated that, of 3.9 million patients visiting a Hospital Emergency Department for dizziness or vertigo in the USA in 2011, 25.7\% were attributable to otological or vestibular causes, costing US $\$ 757$ million. Vestibular dysfunction therefore represents a substantial and increasing burden on healthcare systems.

The most obvious effects of poor vestibular function are oscillopsia and ataxia (see Curthoys and Halmagyi, 1995 for a review); however, vestibular dysfunction involves a more complex syndrome characterized not only by reflex deficits, but also by attention and memory deficits, and anxiety disorders (see Smith et al., 2010 for reviews). It is evident that, in addition to the role of the vestibular system in the vestibulo-ocular and vestibulo-spinal reflexes (VORs and VSRs), the vestibular information provided in the ascending pathways to the limbic system and neocortex is required for an accurate internal representation of the relationship between the self and the spatial environment (Angelaki et al., 2009; chen et al., 2013). In the absence of this information, this internal representation becomes inaccurate, ambiguous, and cognitive performance is affected. The aim of this review is to summarize and critically evaluate the current literature relating to the effects of vestibular function on cognition.

\section{ANIMAL STUDIES OF THE EFFECTS OF VESTIBULAR LESIONS ON MEMORY}

Many of the early animal studies of spatial navigation suggested that non-visual, idiothetic cues such as vestibular and proprioceptive information, along with external, allocentric cues, were used by animals in order to remember how to navigate their way through a familiar environment (Beritoff, 1965; Potegal et al., 1977; Etienne, 1980; Mittelstaedt and Mittelstaedt, 1980; Horn et al., 1981; Potegal, 1982; Miller et al., 1983; Etienne and Jeffery, 2004). It was speculated that vestibular information must be transmitted to the hippocampus, in order to be integrated with other sensory information relevant to spatial memory (Wiener and Berthoz, 1993; Berthoz, 1996; McNaughton et al., 1996; Etienne and Jeffery, 2004). Ultimately it was reported that place cells in the hippocampus, that respond to specific places in the environment, were modulated by vestibular stimulation (Gavrilov et al., 1995; Wiener et al., 1995), which was supported by numerous animal behavioral studies showing that the disruption of normal vestibular function resulted in spatial memory deficits (Potegal et al., 1977; Horn et al., 1981; Potegal, 1982; Miller et al., 1983; Petrosini, 1984; Mathews et al., 1988, 1989; Semenov and Bures, 1989; Chapuis et al., 1992; Ossenkopp and Hargreaves, 1993; Stackman and Herbert, 2002; Wallace et al., 2002; Russell et al., 2003a; Zheng et al., 2003, 2006, 2007, 2008, 2009a,b, 2012a,b; Baek et al., 2010; Besnard et al., 2012; Machado et al., 2012a,b; Smith et al., 2013).

The early studies were open to the interpretation that what appeared to be spatial memory impairment following vestibular damage might be a direct result of oscillopsia, due to VOR deficits, or ataxia, due to VSR deficits. Such deficits never completely compensate even following a unilateral vestibular lesion (Smith and Curthoys, 1989; Curthoys and Halmagyi, 1995); therefore, this was a reasonable possibility. The first sophisticated study of spatial memory following bilateral vestibular lesions was reported by Wallace et al. (2002), who employed a foraging task, in which rats had to remember their way back to a home base, at 2 
weeks post-op. This study, which used chemical lesions of the vestibular labyrinth with intratympanic sodium arsanilate, was well-controlled and used an electronic tracking system to quantify the rats' behavior. They found that rats with bilateral vestibular deaffferentation (BVD) exhibited profound spatial memory deficits in darkness, when visual cues were not available. Over the last decade in particular, many such studies have been conducted at much longer points after the lesion. Some compensation for the vestibular reflex deficits has occurred in the intervening period and yet the spatial memory deficits still persist (Zheng et al., 2006, 2007, 2008, 2009a,b, 2012a,b; Baek et al., 2010). In the study by Baek et al. (2010), which employed the longest post-operative time interval to date, rats that were 14 months post-BVD were more severely impaired in a spatial memory foraging task in darkness than at 5 months post-op. (see Figures 1, 2).

\section{EFFECTS OF UVD vS. BVD IN A SPATIAL MEMORY TASK IN DARKNESS}

Especially important is that the spatial memory deficits exhibited by BVD rats were substantially more severe than for animals with unilateral vestibular deafferentation (UVD) (Zheng et al., 2006, 2009b). Rats with UVD showed spatial memory deficits in darkness at 3 months following the lesion, but performed at levels similar to sham controls at 6 months post-op. (Zheng et al., 2006). However, at 5-6 months post-op., while BVD rats had only minimally impaired performance in a foraging task in light, their performance deteriorated substantially in darkness (Zheng et al., 2009b). By 14 months post-op., rats with the same kind of BVD lesions were severely impaired in darkness (Baek et al., 2010; see Figures 1, 2). In this latter study, even treatment with a cannabinoid receptor agonist, which would normally be expected to cause spatial memory impairment, could not increase the severity of the spatial memory deficits (Figure 2). These deficits in darkness suggest that oscillopsia is not necessary for the spatial navigation impairment to occur.

\section{SPATIAL MEMORY DEFICITS IN LIGHT FOR BVD RATS}

BVD rats have also been demonstrated to exhibit spatial memory deficits in light. At 6 weeks post-op., rats with BVD performed significantly worse than sham controls in a radial arm maze task even in light (Russell et al., 2003a,b). During spatial alternation in a T maze task in light, rats with BVD exhibited some improvement in performance over time, but at 5 months post-op. their percentage of correct responses was still significantly below normal (Zheng et al., 2007). This result was recently replicated by Zheng et al. (2012a,b), using rats at 4-5 months following BVD (see Figure 3).

Besnard et al. (2012) and Machado et al. (2012a,b) have recently demonstrated similar spatial memory deficits in light using the radial arm maze and Y maze in rats that had sequential unilateral chemical labyrinthectomies using sodium arsanilate (Figure 4). In an automated 5 choice serial reaction time task (5-CSRTT), which is a task commonly used to assess attentional performance in light, rats with BVD made significantly fewer correct responses, significantly more incorrect responses, with no more omissions, and responded with a reduced latency, compared to sham controls (Zheng et al., 2009a,b; see Figure 5). This study

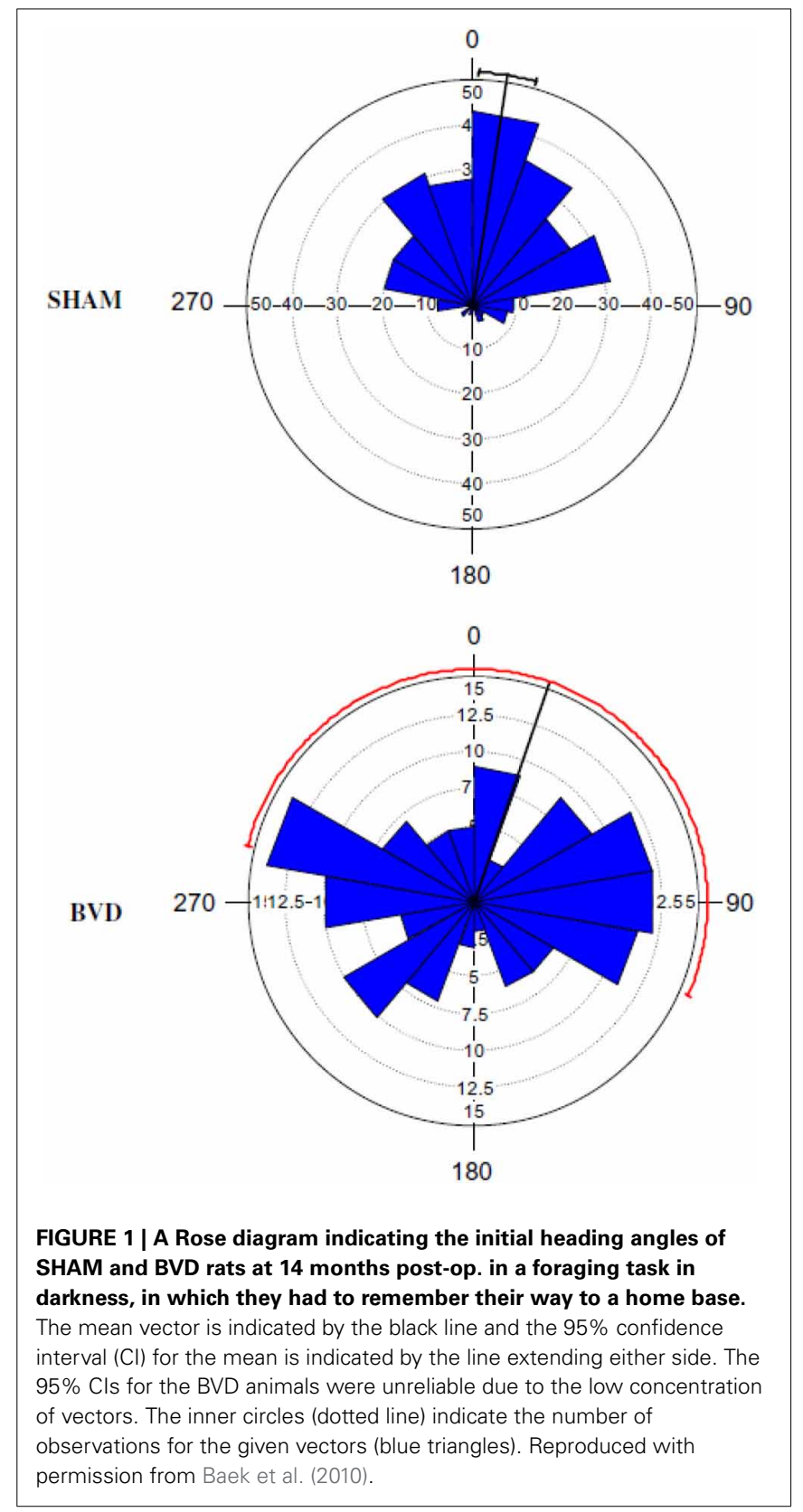

in particular shows that the deficits of BVD rats in these cognitive tasks is not due to an inability to respond, but to incorrect responses.

These studies demonstrate that bilateral vestibular lesions have different effects in different cognitive tasks (i.e., radial arm maze, foraging task, Y and T mazes and 5-CSRTT) and that poor performance is not necessarily contingent upon the animal being in darkness, or light, where the oscillopsia would be expected to be worse, or due to an inability to respond. Therefore, the deficits are more likely to be due to an interaction between reduced cognitive ability and altered sensory input than altered sensory input alone. Studies over the last few years have aimed at elucidating the extent to which the spatial memory deficits may be due to other 


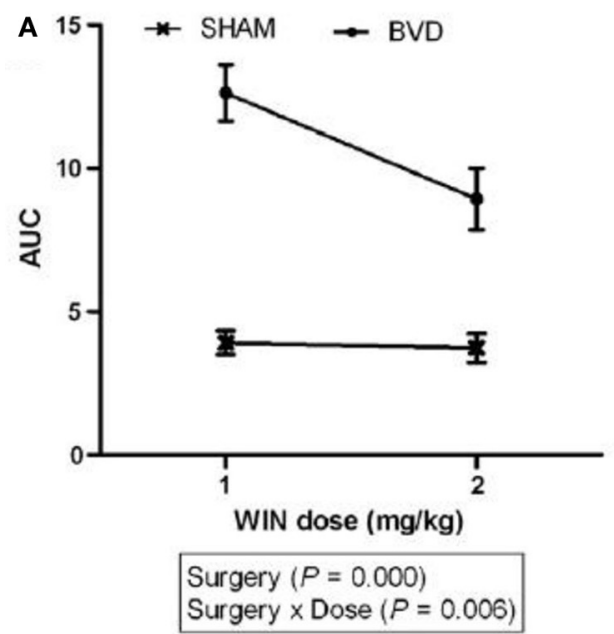

B

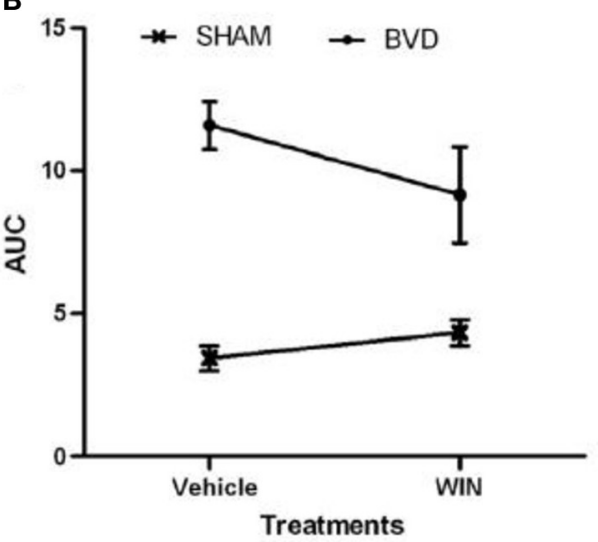

Surgery $\times$ Treatment $(P=0.014)$

C

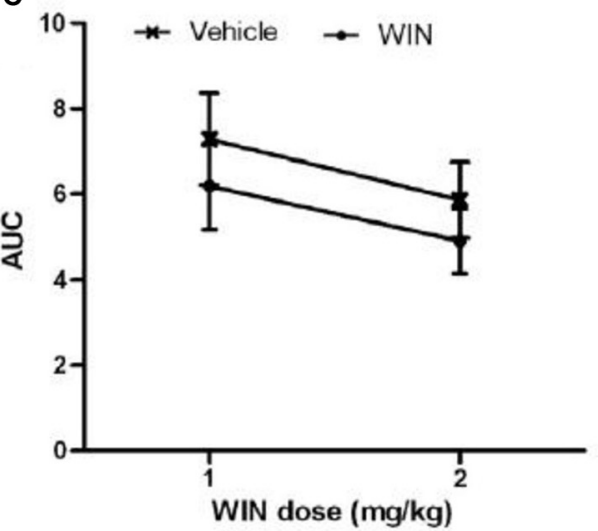

Dose $(P=0.004)$

FIGURE 2 | The area under the curve (AUC) for the number of errors exhibited in the same foraging task described in Figure 1, for the sham and BVD animals at 14 month post-op. in darkness, showing the effects of surgery, drug treatment with a cannabinoid receptor agonist, WIN55,212-2 (which one would normally expect to make spatial memory worse), and their interaction. (A) Effects of surgery; (B) Drug treatment; and (C) Drug dose. Data are represented as mean \pm s.e.m. Reproduced with permission from Baek et al. (2010).

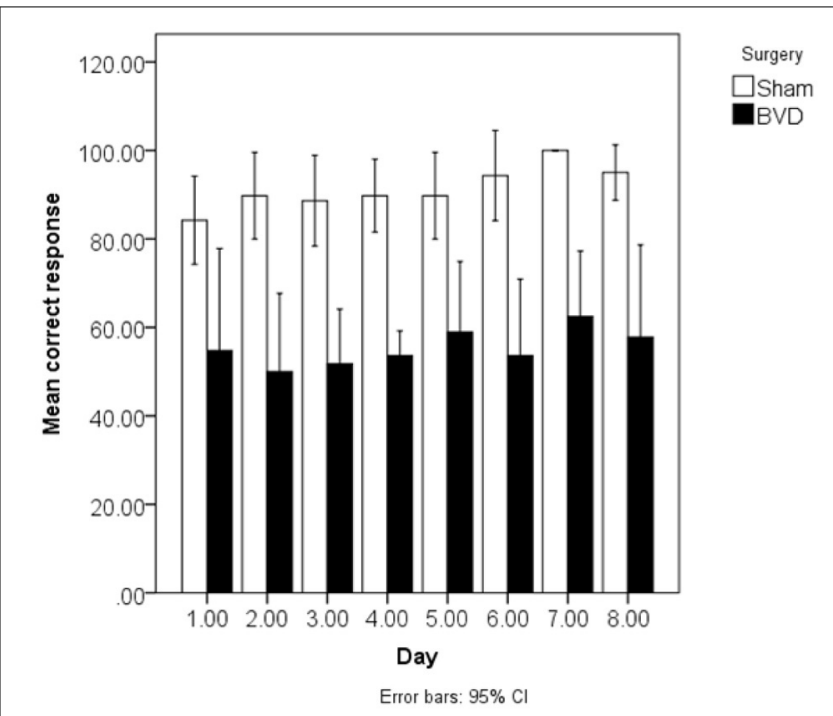

FIGURE 3 | Mean \% correct responses in the spatial T maze task in light over 8 days for the BVD and sham animals at 4-5 months post-op. Reproduced with permission from Zheng et al. (2012a,b). Data are expressed as means \pm a $95 \%$ confidence interval.

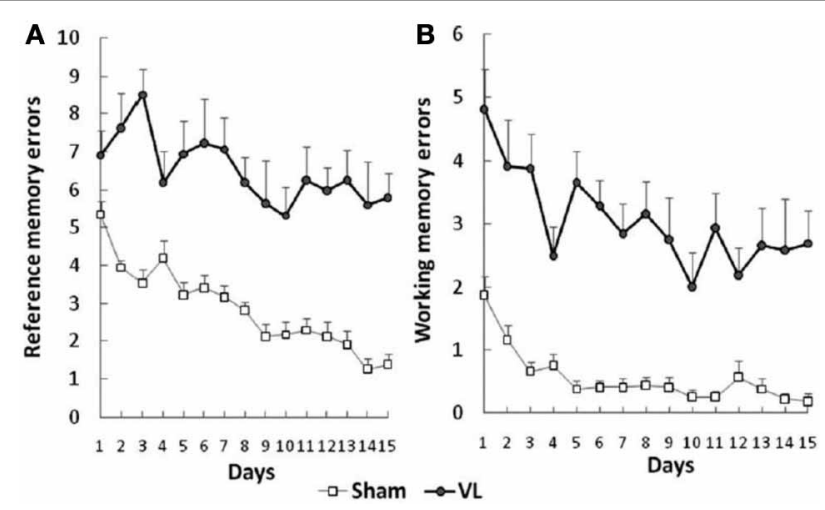

FIGURE 4 | Effects of sequential unilateral vestibular lesions on performance of rats, compared to sham controls, in a radial arm maze task. (A) Number of reference memory errors. (B) Number of working memory errors. Data are represented as mean \pm s.e.m. Reproduced with permission from Besnard et al. (2012).

complications of BVD, such as changes in locomotor activity and anxiety.

\section{POSSIBLE RELATIONSHIP BETWEEN SPATIAL MEMORY DEFICITS AND LOCOMOTOR HYPERACTIVITY}

Most studies of rats with BVD indicate that they are hyperactive rather than hypoactive (Russell et al., 2003a,b; Goddard et al., 2008; Zheng et al., 2008, 2009a,b, 2012a,b; Baek et al., 2010; Besnard et al., 2012; Stiles et al., 2012; Machado et al., 2012b; see Figure 6). While this makes it difficult to explain poor performance in cognitive tasks in terms of an inability to move, it is conceivable that the hyperactivity prevents the animals from performing accurately in these various cognitive tasks. However, 

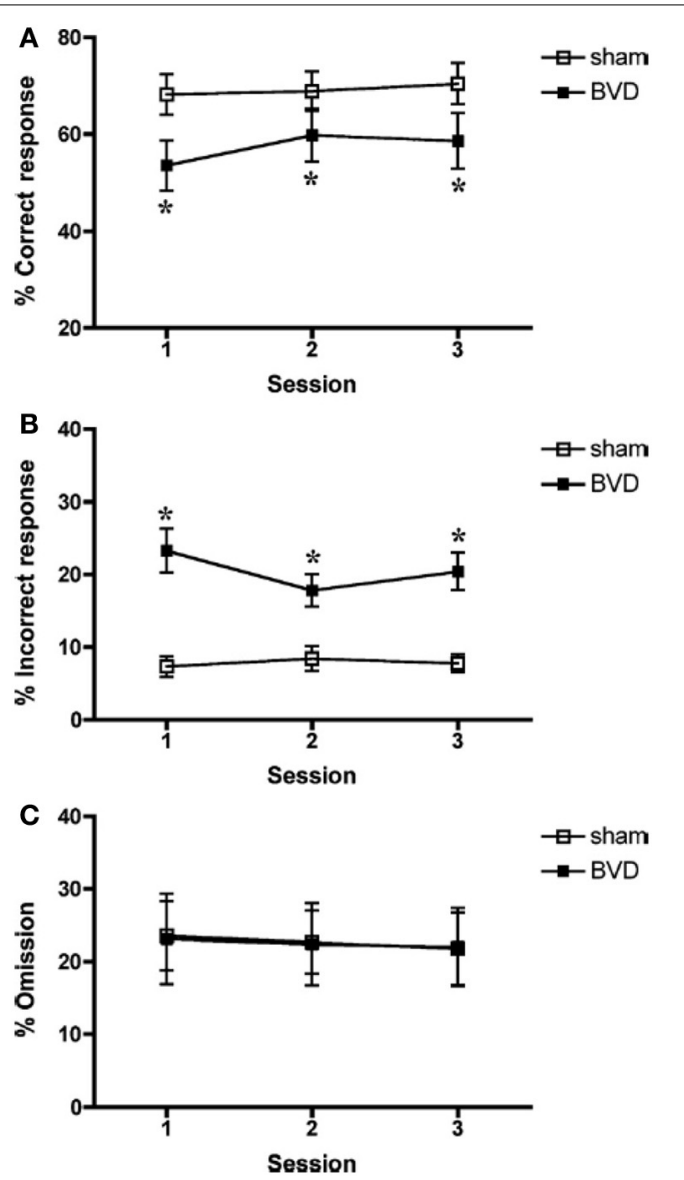

FIGURE 5 | Percentage of correct responses (A), incorrect responses (B), and omissions (C) for sham (open square) and BVD rats (closed square) in a $\mathbf{5}$ choice serial reaction time task in light. Data are expressed as means \pm s.e.m. Asterisks indicate significant differences. Reproduced with permission from Zheng et al. (2009a,b).

Baek et al. (2010) used regression analyses to show that the poor performance of BVD rats in a foraging task could not be predicted by their hyperactivity (Figure 7 ). We have recently revisited this issue using multiple linear and random forest regression and found that hyperactivity cannot predict the poor performance of rats in a spatial $\mathrm{T}$ maze alternation task, but that the best predictors were whether the animals had received a BVD and the duration of their rearing in an open field maze (Smith et al., 2013; see Figure 8). These results suggest that the poor spatial memory performance of BVD rats cannot be explained by their locomotor hyperactivity. Further evidence in support of this conclusion is that even rats treated with diazepam and exhibiting anxiolytic behavior, still demonstrated the same spatial memory deficits in a radial arm maze task (Machado et al., 2012b).

\section{POSSIBLE RELATIONSHIP BETWEEN SPATIAL MEMORY DEFICITS AND} ANXIETY

It is possible that the association between vestibular dysfunction and anxiety and depression has some connection with the observed cognitive deficits that accompany vestibular
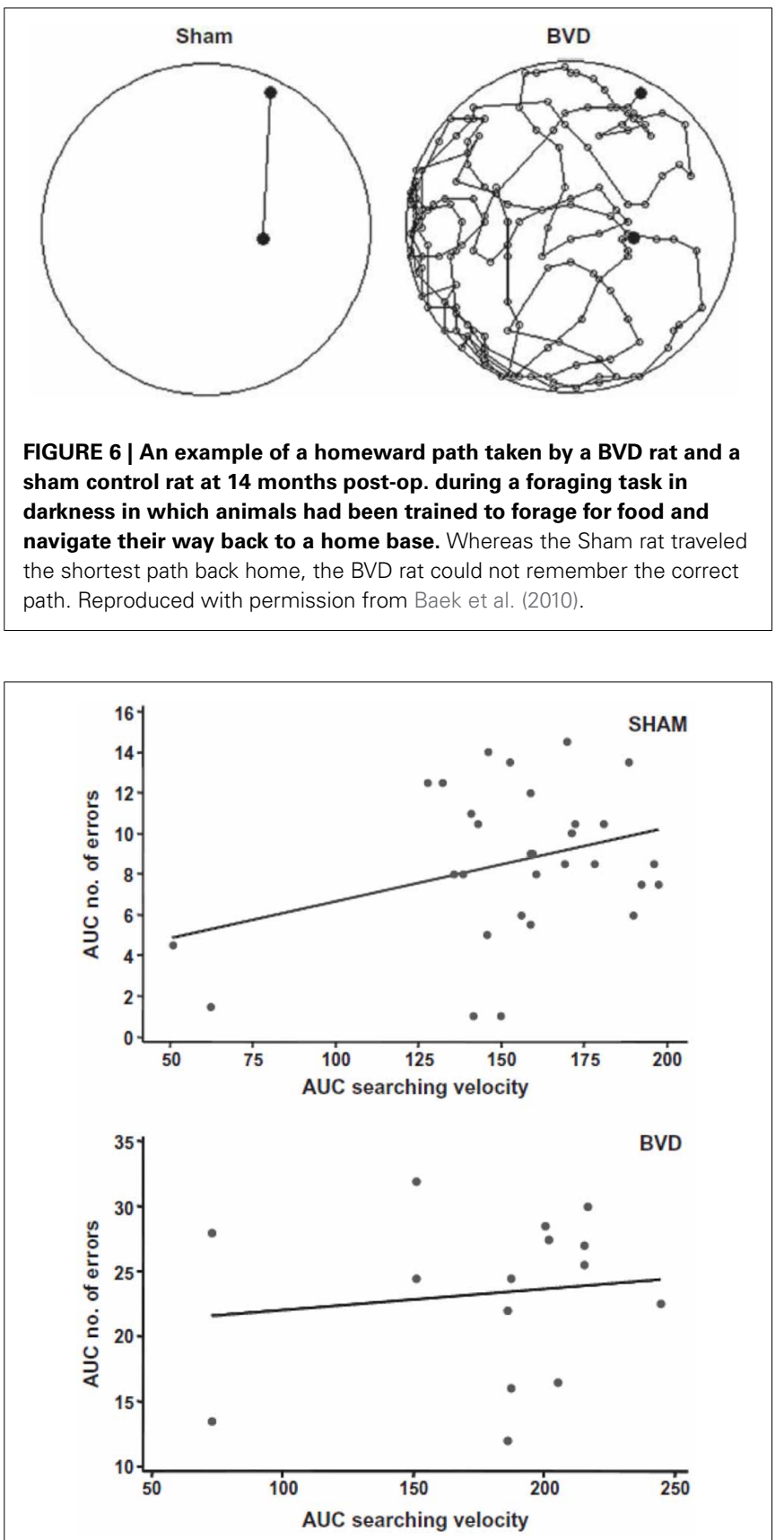

FIGURE 7 | A scatter graph showing a simple linear regression analysis to predict the number of errors made by all of the sham or BVD animals (in terms of the area under the curve) from their searching velocities in the foraging task, as an index of their locomotor hyperactivity. There was no significant prediction of spatial memory error from locomotor activity. Reproduced with permission from Baek et al. (2010).

lesions (Balaban and Thayer, 2001; Balaban, 2002; Staab and Ruckenstein, 2003; Staab, 2006). However, at least in animal studies, there is some evidence to disentangle anxiety and cognition in relation to BVD. Machado et al. (2012b) used the black and white box test to show that rats with BVD exhibited increased 


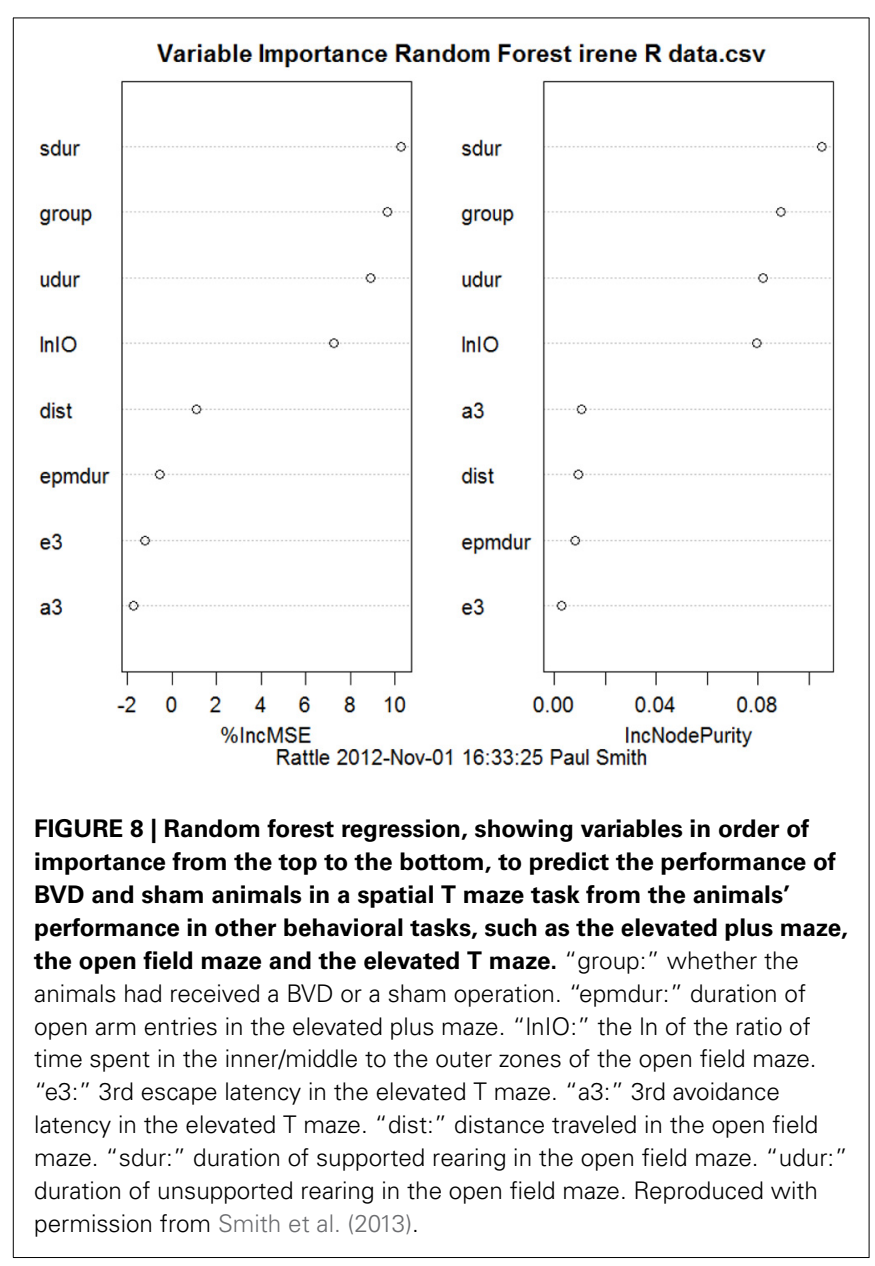

anxiety and then administered diazepam to reduce it. Although the diazepam appeared to decrease the animals' anxiety, it had no effect on their poor performance in the radial eight-arm maze (Figure 9). Zheng et al. (2012a,b) attempted a similar experiment using the non-benzodiazepine anxiolytic drug, buspirone. In this case, the BVD animals did not exhibit increased anxiety in the elevated plus maze and buspirone had no effect on the time spent in the open arms of the maze, but neither did it have any effect on the animals' poor performance in a spatial forced alternation T maze task. Similarly, an anxiogenic drug, FG-7142, had no effect either on their spatial memory performance. Both of these studies suggest that, at least in animals, spatial memory deficits following BVD may be independent of anxiety.

\section{VESTIBULAR vs. AUDITORY DAMAGE}

One of the important limitations of the animal studies in this area is that chemical or surgical lesions of the vestibular labyrinth usually involve damage to the cochlea as well, and therefore it is possible that any cognitive effects of the lesions are partly due to hearing loss. For example, auditory stimulation, including noise trauma, has been reported to affect place cell function (Sakurai, 1990, 1994; Goble et al., 2009). For this reason, in most of our behavioral studies, sham control animals have their tympanic

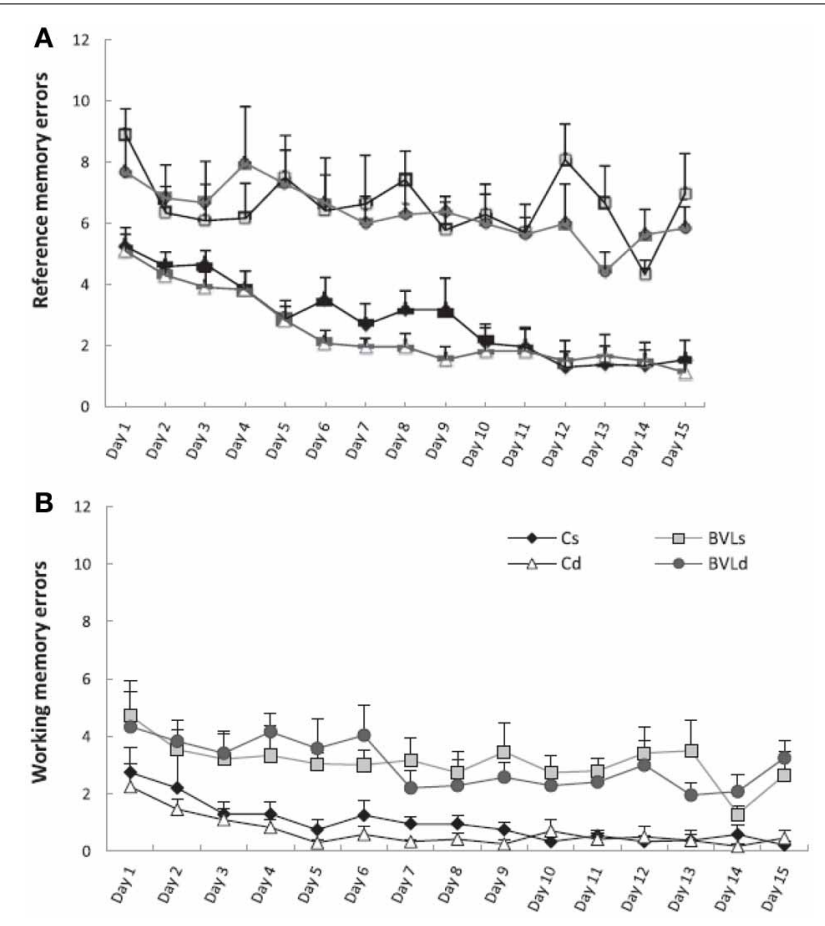

FIGURE 9 | Effects of $0.5 \mathrm{mg} / \mathrm{kg}$ diazepam, which was shown to have an anxiolytic effects, on spatial memory performance in a radial arm maze of bilateral vestibular lesion (BVL) and sham $\mathbf{C}$ rats. (A) Number of reference memory errors. (B) Number of working memory errors. Cs, control saline; Cd, control diazepam; BVLs, BVL saline; BVLd, BVL

diazepam. Diazepam did not reduce the spatial memory deficits of the BVL rats. Data are expressed as means \pm s.e.m. Reproduced with permission from Machado et al. (2012b).

membranes removed so that sound is no longer transmitted effectively to the malleus, incus and stapes. This can serve as only a partial auditory control, however, because some sound will still be transmitted to the cochlea. Nonetheless, we have consistently found that rats without vestibular lesions but with the tympanic membrane removed perform significantly better in cognitive tasks than animals with vestibular lesions (Zheng et al., 2006, 2007, 2008, 2009a,b, 2012b; Baek et al., 2010). This result suggests that hearing loss is not the major cause of the spatial memory deficits in animals subjected to BVD, and is consistent with the results from studies of patients with vestibular dysfunction (e.g., Brandt et al., 2005). In addition, animal studies, using different kinds of aminoglycosides (i.e., streptomycin and neomycin) with different toxicities for the auditory and vestibular hair cells, have shown that the effects of auditory and vestibular lesions on learning and memory are different (Schaeppi et al., 1991). In a radial arm maze task, rats treated with streptomycin, which lesioned the auditory and the vestibular systems, exhibited impaired working memory; however, rats treated with neomycin, which lesioned only the auditory system, did not (Schaeppi et al., 1991). In our tinnitus studies we have found that a unilateral acoustic trauma has no significant effect on spatial memory (Zheng et al., 2011). 
It is not clear whether the cognitive deficits associated with vestibular dysfunction in animals are limited to spatial memory impairment. Some animal studies using surgical BVD have also reported deficits in attention (Zheng et al., 2009a) and in object recognition memory that has no spatial component (Zheng et al., 2004). However, others using sequential chemical UVDs have reported no deficits in object recognition memory (Besnard et al., 2012); therefore, this issue remains to be resolved due to methodological differences between the existing studies.

\section{HUMAN STUDIES OF THE VESTIBULAR LESIONS ON MEMORY}

One of the first clinical studies of cognitive function following vestibular loss was reported by Grimm et al. (1989). They described patients with a perilymph fistula syndrome, who reported symptoms such as positional vertigo but also a variety of psychological symptoms, including memory and attention deficits. From a total of 102 patients, more than $85 \%$ of them reported memory loss. The patients had a normal level of intellectual function; however, their performance on digit symbol, block design, paired associate learning and picture arrangement tasks, was impaired. Following this, several studies in the 1990's examined the effects of vestibular damage on spatial navigation in humans. They showed that patients with vestibular disorders exhibited deficits in path navigation (Peruch et al., 1999; Cohen, 2000; Cohen and Kimball, 2002; Borel et al., 2004). However, the tasks involved movement, and therefore it could be argued that the deficits resulted from a complex interaction between cognition and postural control. Other studies examined cognitive performance more directly. Black et al. (2004) found that memory problems were common in patients with vestibular loss due to gentamicin ototoxicity. Jauregui-Renaud and colleagues have published a number of studies reporting that patients with vestibular disorders have high rates of depersonalization/derealization symptoms, which include difficulty focussing attention and thoughts seeming blurred (Sang et al., 2006; Jauregui-Renaud et al., 2008a,b; see Gurvich et al., 2013, for review). Other studies have shown that as postural tasks become more challenging, patients with vestibular disorders exhibit deficits in reaction time and memory (Yardley et al., 2001, 2002; Redfern et al., 2004). In a study by Redfern et al. (2004), patients with unilateral vestibular loss showed large increases in complex and inhibitory reaction time, even while seated. A similar result was reported by Talkowski et al. (2005).

\section{BILATERAL vs. UNILATERAL VESTIBULAR LESIONS}

The most sophisticated and well-controlled studies of spatial memory following vestibular lesions in humans, have been reported by Schautzer et al. (2003) and Brandt et al. (2005), who examined the performance in a spatial memory test, the virtual Morris water maze, of 10 patients with bilateral vestibular loss and compared them with age-, sex- and education-matched controls. The task involved moving only a cursor on a computer screen, using a mouse; therefore, performance in the spatial memory task could not have been confounded by VSR deficits. The patients had received bilateral vestibular neurectomies 5-10 years previously for the treatment of neurofibromatosis type 2 .
They found that the patients with bilateral vestibular loss showed impaired performance in the task when they had to remember a navigation path to a previously visible target; however, they showed no deficit when the target was visible, therefore the effect was specific to memory (see Figure 10). Brandt et al. used the Weschler memory test to show that the patients had normal or above normal non-spatial memory performance. Compared to the controls, the patients also exhibited a significant decrease in the volume of the hippocampus $(16.9 \%)$. This effect was bilateral, specific to the hippocampus and there was no significant reduction in the total brain volume or in the volume of gray matter or white matter, only a significant increase in cerebrospinal fluid volume. Importantly, only one of the BVD patients had total post-operative hearing loss.

In a study of patients with UVD, Hüfner et al. (2007) reported results from the virtual Morris water maze task that were more complex. During place learning, males with a right UVD and females with a left UVD exhibited a significantly smaller decrease in heading error over the repeated trials compared to the controls and other UVD groups. In addition, inspection of the swim paths showed that only 2 out of the 8 right UVD patients used direct paths to the platform, compared to 12 out of the 16 control subjects, a difference that was statistically significant. In the probe trial, the right UVD patients were found to have a greater heading error than the left UVD patients or control subjects. Finally, in the cued navigation, females with a left UVD performed worse than the other groups in the first visible platform trial. By contrast with the study of Brandt et al. (2005) of patients with BVD, Hüfner et al. (2007) found no significant differences in the hippocampal volume of UVD patients compared to controls. In a later study, Hüfner et al. (2009) reported some subtle deficits in spatial memory in patients with UVD as well as an atrophy of the ipsilateral supramarginal nucleus, the postcentral and superior temporal gyrus and the MT/V5 area, as well as the contralateral thalamus and tegmentum of the mesencephalon. However, zu Eulenburg et al. (2010) reported that patients who

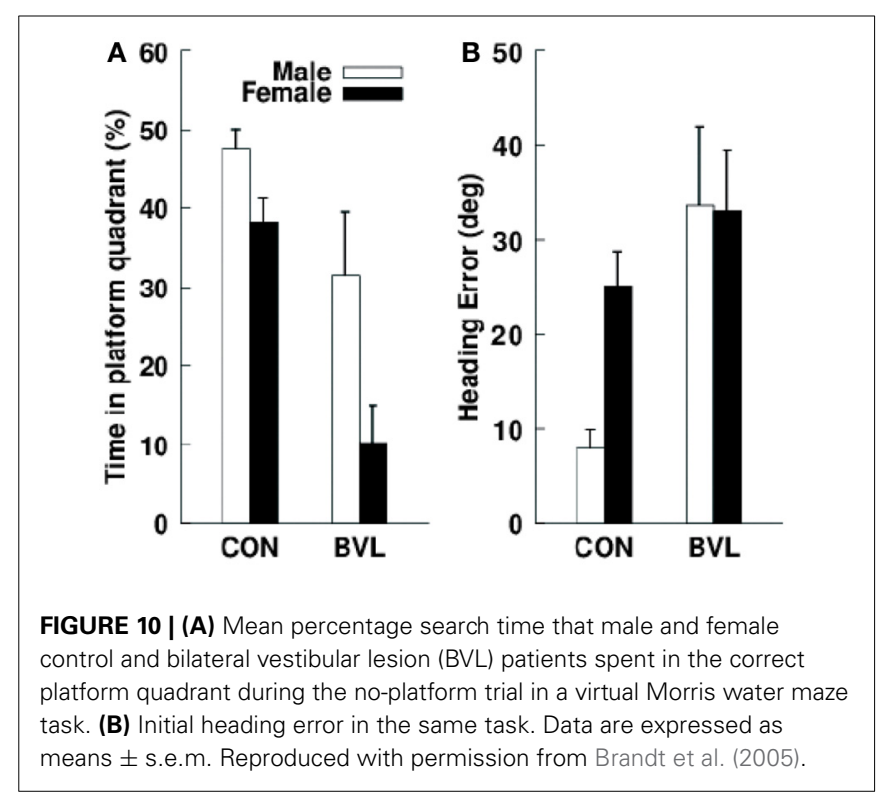


had recovered from unilateral vestibular neuritis, exhibited a significant decrease in the volume of the left posterior hippocampus, irrespective of the laterality of the vestibular neuritis. Helmchen et al. (2013) have recently reported the results of a resting state fMRI study of patients with vestibular neuritis. They identified a network of brain regions that was significantly different from controls, including the parietal lobe, the medial aspect of the superior parietal lobule, the posterior cingulate cortex, the middle frontal gyrus, the middle temporal gyrus, the parahippocampal gyrus, the anterior cingulate cortex, the insular cortex, the caudate nucleus, the thalamus and the midbrain.

Consistent with these studies, Hüfner et al. (2010) reported structural changes in the hippocampi of professional dancers and slackliners, who have unusual spatial memory experience. Hufner et al. found that trained subjects exhibited a smaller anterior volume, and a larger posterior volume, in the hippocampal formation, although they showed no difference in spatial memory compared to controls, according to the virtual Morris water maze test.

It is apparent from these studies that the volume of the human hippocampus is sensitive to vestibular input. While the effects of BVD are the most dramatic (Brandt et al., 2005), the effects of unilateral vestibular loss are more circumscribed (Hüfner et al., 2007; zu Eulenburg et al., 2010; Helmchen et al., 2013).

Vestibular disorders have also been reported to impair mental imagery tasks that involve imagined rotations or translations of objects relative to the environment, which are also spatial in nature (Péruch et al., 2011). Grabherr et al. (2011) found that only patients with bilateral vestibular loss, and not unilateral vestibular loss, exhibited impaired ability to mentally transform images of bodies and body parts compared to controls.

It is not entirely clear whether the cognitive deficits associated with vestibular dysfunction in humans are limited to spatial memory impairment. While some studies have reported that other aspects of memory, attention and general intelligence are normal (Schautzer et al., 2003; Brandt et al., 2005), others have reported deficits in attention and concentration (Sang et al., 2006; Jauregui-Renaud et al., 2008a,b) and even dyscalculia (Risey and Briner, 1990-1991; Andersson et al., 2002, 2003; Yardley et al., 2002; see Smith, 2012 for a review).

\section{POSSIBLE CONNECTION WITH VESTIBULAR REFLEX DYSFUNCTION AND VERTIGO}

As with the animal studies, it is possible that any memory impairment following vestibular damage might simply be a result of vestibular reflex deficits, for example, the inability to see clearly due to oscillopsia or ataxia as a consequence of impaired VORs and VSRs (respectively) (Gizzi et al., 2003). However, studies such as those by Schautzer et al. (2003) and Brandt et al. (2005) were conducted 5-10 years following bilateral vestibular neurectomy. Although the patients would never have recovered normal VOR and VSR function, they would have compensated for the severe acute symptoms (Smith and Curthoys, 1989; Curthoys and Halmagyi, 1995).

Given the severity of some vestibular disorders such as Ménière's disease, it is possible that any cognitive dysfunction is an indirect consequence of symptoms such as vertigo. However, studies of patients with chronic vestibular loss without vertigo, have reported that the patients still exhibit spatial memory impairment (Guidetti et al., 2008). Overall, it seems that patients with at least bilateral vestibular loss, suffer from cognitive problems, particularly spatial memory impairment, that are not simply a direct result of vestibular reflex dysfunction (see Smith et al., 2005a,b; Hanes and McCollum, 2006; Smith et al., 2009, 2010; Gurvich et al., 2013, for reviews).

\section{POSSIBLE CONNECTION WITH ANXIETY AND DEPRESSION}

In the case of humans, it is much more difficult to separate poor performance in cognitive tests from emotional disorders. Vestibular dysfunction in humans is often associated with anxiety disorders, including panic attacks and phobias, as well as depression (Eagger et al., 1992; Asmundson et al., 1998; Balaban and Thayer, 2001; Balaban, 2002; Furman and Jacob, 2001; Monzani et al., 2001; Grunfeld et al., 2003; Persoons et al., 2003; Pollak et al., 2003; Godemann et al., 2004a,b, 2009; Best et al., 2006; Staab, 2006; see Gurvich et al., 2013, for review). Anxiety may be a direct consequence of vestibular dysfunction; however, it has also been reported that anxiety disorders can cause dizziness of vestibular origin (Asmundson et al., 1998; Venault et al., 2001; Bolmont et al., 2002; Staab et al., 2002; Tecer et al., 2004; Best et al., 2006; Furman et al., 2006) and antidepressants such as selective serotonin reuptake inhibitors (SSRIs) have been reported to relieve dizziness associated with anxiety (Staab et al., 2002; Simon et al., 2005; Horii et al., 2007). It possible that emotional disorders arise indirectly from cognitive impairment. However, Halberstadt and Balaban (2006) have reported that the same neurons in the dorsal raphe nucleus that release serotonin, send projections into the amygdala, as well as the brainstem vestibular nucleus. This finding suggests that changes in emotional tone may directly influence the vestibular system.

It is worth noting here that the hippocampus is as much an emotional brain region as one that contributes to spatial memory (Gray and McNaughton, 2003). While the rat dorsal hippocampus (approximately equivalent to the posterior hippocampus in humans) is involved in spatial information processing and spatial memory, the rat ventral hippocampus (approximately equivalent to the anterior hippocampus in humans) processes emotional stimuli (Bannerman et al., 1999, 2004). Therefore, it may be difficult to disentangle the effects of vestibular loss on cognition and emotion.

\section{EFFECTS OF VESTIBULAR LESIONS ON HEAD DIRECTION CELL AND PLACE CELL FUNCTION}

Taube and colleagues have shown that bilateral inactivation of the vestibular labyrinth, using intratympanic tetrodotoxin, results in the dysfunction of thalamic head direction cells (Stackman and Taube, 1997; see Brown et al., 2002 for a review). In other studies, they have shown that head direction cell activity is degraded during inverted locomotion (Calton and Taube, 2005) and as a result of the loss of vestibular information from either the otoliths (Yoder and Taube, 2009) or the semi-circular canals (Muir et al., 2009). Also using intratympanic tetrodotoxin, Stackman et al. (2002) first reported that loss of vestibular function resulted in a disruption of the selective firing of hippocampal place cells in 
alert rats. One of the most important aspects of this result was that the disruption to place cell firing patterns was immediate, and it recovered over time, indicating that long-term changes in hippocampal structure were unnecessary for the changes in place cell function. This result was replicated by Russell et al. (2003b) using permanent surgical BVD in rats.

Hippocampal theta rhythm is a large amplitude, quasisinusoidal EEG rhythm of $\sim 5-12 \mathrm{~Hz}$ which is believed to serve a cohesive function for the firing of hippocampal place cells (Hasselmo, 2005; Vertes, 2005). Many studies in alert animals have reported that theta rhythm in the frequency range of 6$9 \mathrm{~Hz}$ can be recorded during movement (see Zou et al., 2009 for a review). In fact, theta frequency has been shown to increase with increasing speed of locomotion (Jeewajee et al., 2008; Lever et al., 2009). Very few studies have investigated the effects of vestibular lesions on theta rhythm. Stackman et al. (2002) investigated theta in one rat in a study in which they transiently inactivated the vestibular system. In the one animal in which they analyzed theta, they found no significant difference from control animals. Russell et al. (2006) used permanent surgical BVD to investigate the effects of vestibular loss on theta rhythm. In contrast to Stackman et al. (2002), they found that hippocampal theta rhythm was severely disrupted. Not only was the power of theta reduced following BVD, but the quasi-sinusoidal character of the waveform was corrupted. Although the BVD animals were hyperactive, theta rhythm was abnormal across the entire range of movement velocities. These results have recently been replicated by Neo et al. (2012), who tried but failed to reverse the spatial memory and emotional deficits caused by BVD by electrically stimulating the septum in order to provide an artificial theta rhythm. Tai et al. (2012) also recently showed that rats that are administered sodium arsanilate intratympanically exhibit a reduction in theta power.

Taken together, these animal studies support the view that vestibular information is important for the generation of spatial memories (Wiener and Berthoz, 1993; Berthoz, 1996; McNaughton et al., 1996, 2006; Etienne and Jeffery, 2004; Smith et al., 2005a,b, 2009, 2010). It is still unclear how vestibular information reaches the hippocampus. Electrical stimulation of one vestibular labyrinth or of the vestibular nucleus has been reported to evoke field potentials, single unit activity and neurotransmitter release in the hippocampus, albeit with a long latency (Horii et al., 1994, 2004; Cuthbert et al., 2000). Caloric or electrical stimulation of the human labyrinth has been shown to cause activation of the hippocampus (Vitte et al., 1996; De Waele et al., 2001) and glucose uptake is reduced in the hippocampus in patients with acute vestibular neuritis (Bense et al., 2001). The thalamus is certain to be one important relay station for the transmission of at least some ascending vestibular information. However, the number of different vestibulo-hippocampal pathways and their precise nature, remains to be determined (Smith, 1997; see Shinder and Taube, 2010 and Hufner et al., 2011 for recent reviews). It must also be kept in mind that the hippocampus is only one part of a highly complex system of limbic-neocortical pathways that are responsible for spatial memory (Guldin and Grusser, 1998; Hanes and McCollum, 2006; Gu et al., 2007; Shinder and Taube, 2010; Lopez and Blanke, 2011). In humans, fMRI has revealed that areas of significant activation by galvanic vestibular stimulation (GVS) include the posterior insula, the retroinsular regions, the superior temporal gyrus, parts of the inferior parietal lobule, the intraparietal sulcus, the post-central and pre-central gyrus, the anterior insular, the inferior frontal gyrus, the anterior cingulate gyrus, the precuneus and the hippocampus (Lobel et al., 1998; see Karnath and Dieterich, 2006 for a review). Activation of cortical networks during GVS is not symmetrical; it appears to be stronger in the non-dominant hemisphere, in the hemisphere ipsilateral to the stimulated ear, and in the hemisphere ipsilateral to the fast phase of vestibular nystagmus (see Karnath and Dieterich, 2006 for a review).

Despite the finding by Brandt et al. (2005) that patients with BVD exhibit a bilateral atrophy of the hippocampus, studies in BVD rats have so far failed to detect such a change. Using a sequential chemical BVD procedure, Besnard et al. (2012) found no significant change in hippocampal volume using MRI. Likewise, Zheng et al. (2012a) could find no change hippocampal volume or neuronal number using stereology. Nonetheless, in unpublished studies, we have found a significant decrease in dendritic length in the hippocampi of BVD rats. One possibility is that hippocampal volume is maintained in rats following BVD due to their locomotor hyperactivity, since movement is known to stimulate hippocampal neurogenesis. Interestingly, Zheng et al. (2012a) observed a significant increase in cell proliferation in the rat hippocampus following BVD. Besnard et al. (2012) also reported an increase in NMDA receptor density and a decrease in affinity in BVD rats. Although Zheng et al. (2013) did not find significant differences in glutamate receptor subunit expression in rats with BVD, principal component analysis did reveal subtle changes in the relationship between different NMDA receptor subunits (Smith and Zheng, 2013). Because Besnard et al. (2012) used autoradioradiography with beta imaging, their results may reflect functional NMDA receptors rather than the total receptor pool.

\section{EFFECTS OF ARTIFICIAL VESTIBULAR ACTIVATION ON MEMORY IN HUMANS}

A small literature exists on the use of low amplitude, noisy GVS to enhance cognition in humans. The overlaying of a noise signal on a galvanic stimulus, termed "noisy GVS," is based upon the concept of stochastic resonance, in which a sub-threshold sensory stimulus can be made to exceed a fixed threshold if a Gaussian noise signal, with a frequency much higher than the sub-threshold stimulus, is superimposed upon it (Moss et al., 2004).

Bächtold et al. (2001) was the first to report that caloric vestibular stimulation (CVS) could improve verbal and spatial memory in humans, and the effect was greater for right ear irrigation. However, CVS induces vestibular reflexes and therefore it is difficult to separate those effects from cognitive performance. Falconer and Mast (2012) have recently reported that CVS can enhance performance in an egocentric transformation task.

In a later study, Wilkinson et al. (2008) investigated whether noisy, low intensity, bipolar GVS, which was sub-threshold for the activation of the vestibular reflexes, could affect memory for faces. They found that the mean reaction time was shorter for the GVS 
groups compared to the sham controls, but that the largest reduction was for the anode on the left ear and the cathode on the right ear. They concluded that GVS can improve memory for faces, perhaps by increasing blood flow to the right temporal and parietal cortices. This effect of GVS on memory was unlikely to be due to non-specific arousal since the electrical stimulation was subthreshold, the memory improvement was greater for the anode on the left, and improvement was found only when a noise signal was added to the GVS. Wilkinson and colleagues have also found that noisy GVS can attenuate prosopagnosia (Wilkinson et al., 2005) and figure copying deficits (Wilkinson et al., 2010). In the most recent study involving two patients with visuo-spatial neglect, GVS was found to have a lasting beneficial effect in a target cancellation task (Zubko et al., 2013). In one of the most systematic studies to date, Dilda et al. (2012) found that suprathreshold GVS significantly increased the error rates for match-to-sample and perspective-taking tasks compared to a subthreshold GVS group; however, reaction time, dual tasking, mental rotation and manual tracking were not significantly affected. Subthreshold GVS had no significant effect on cognitive performance compared to the pre-stimulus conditions.

At the present, there is very little evidence relating to how noisy GVS affects memory. It is not clear whether the effect has any relationship to the effects of vestibular lesions on spatial memory. One possibility is that any beneficial effect of GVS is merely a result of the fact that vestibular information reaches many regions of the neocortex (Bense et al., 2001) and that it will probably cause a change in the integration of sensory information (Wilkinson et al., 2008). However, given the importance of vestibular information to spatial memory, sub-threshold GVS may somehow "prime" the brain to process and store new information. Wilkinson et al. (2012) have recently reported that GVS increased the amplitude of the N170 potential and the power of delta and theta EEG during a face processing task. It is noteworthy that many of these effects of GVS are not restricted to spatial attention or memory. A more recent study by Kim et al. (2013) also supports the idea that GVS modulates neural oscillations.

\section{CONCLUSIONS}

Over the last 12 years in particular, a substantial body of evidence has accumulated to suggest that the loss of vestibular function results in cognitive disorders, especially spatial memory deficits that cannot easily be attributed to the direct effects of reflex dysfunction, motor control problems or hearing loss. The spatial memory deficits appear to be most striking in the case of BVD, where there is a complete loss of vestibular function, although there are many more animal studies than human studies to substantiate this. It will be particularly important in future studies to further investigate the effects of unilateral and bilateral vestibular loss in humans, on different types of cognitive function.

In animals at least, the spatial memory deficits appear to be independent of anxiety, although this is less conclusive in humans. One reason to be cautious about disentangling the effects of vestibular damage on cognition and emotion, is that the hippocampus is deeply involved in both (Gray and McNaughton, 2003). While lesions of the dorsal hippocampus in rats result in spatial memory deficits and locomotor hyperactivity, lesions of the ventral hippocampus result in reduced anxiety in the elevated plus maze and hyponeophagia (Bannerman et al., 2002). It is intriguing that BVD, in addition to causing spatial memory deficits and locomotor hyperactivity in rats, has been reported to cause both reduced anxiety in the elevated plus and $\mathrm{T}$ mazes (Zheng et al., 2008; Neo et al., 2012) and hyponeophagia (Zheng et al., 2008). This might suggest that BVD results in behavioral effects that are similar to both dorsal and ventral hippocampal lesions and that it may be very difficult to disentangle them completely.

The cognitive effects of vestibular loss appear to be due mainly to the important contribution that the vestibular system makes to neurons involved in spatial navigation and memory, such as head direction cells and place cells, although exactly how this information is used remains to be determined. Information from the otoliths as well as the semi-circular canals seems to be necessary for the normal function of head direction cells; however, so far the different contributions of the otoliths and semi-circular canals to hippocampal place cell function have not been investigated. Furthermore, despite the attention to the thalamus and hippocampus, many different areas of the limbic system and neocortex are involved in these spatial memory processes. Since grid cells in the entorhinal cortex are thought to be responsible for the place fields of hippocampal place cells (see Giocomo et al., 2011 for a review), it might be predicted that BVD would severely disrupt grid cell firing; however, this has not been investigated to date. Future studies will need to specifically address how vestibular information is transmitted to the dorsal and ventral hippocampus in rats and the extent to which otolithic vs. semi-circular canal input is represented in different areas of the hippocampus and entorhinal cortex. At present, we know that vestibular input is necessary for the normal function of the hippocampus but we do not understand how this input is being used.

At present there is some evidence that artificial activation of the vestibular system, using noisy GVS, can modulate memory. However, at present this literature is small and it is unclear whether this effect, when it occurs, is related to the same mechanisms by which vestibular lesions affect memory.

\section{ACKNOWLEDGMENTS}

This research has been supported by the Marsden Fund and the New Zealand Neurological Foundation. Yiwen Zheng was a recipient of the Health Research Council Sir Charles Hercus Fellowship.

\section{REFERENCES}

Agrawal, Y., Carey, J. P., Della Santina, C. C., Schubert, M. C., and Minor, L. B. (2009). Disorders of balance and vestibular function in US adults: data from the National Health and Nutrition Examination Survey, 2001-2004. Arch. Int. Med. 169, 938-944. doi: 10.1001/archinternmed.2009.66

Andersson, G., Hagman, J., Talianzadeh, R., Svedberg, A., and Larsen, H. C. (2002). Effects of cognitive load on postural control. Brain Res. Bull. 58, 135-139. doi: 10.1016/S0361-9230(02)00770-0

Andersson, G., Hagman, J., Talianzadeh, R., Svedberg, A., and Larsen, H. C. (2003). Dual task study of cognitive and postural interference in patients with vestibular disorders. Otol. Neurotol. 24, 289-293. doi: 10.1097/00129492200303000-00026

Angelaki, D. E., Klier, E. M., and Snyder, L. H. (2009). A vestibular sensation: probabilistic approaches to spatial perception. Neuron $64,448-461$. doi: 10.1016/j.neuron.2009.11.010 
Asmundson, G. J., Larsen, D. K., and Stein, M. B. (1998). Panic disorder and vestibular disturbance: an overview of empirical findings and clinical implications. J. Psychosom. Res. 44, 107-120. doi: 10.1016/S0022-3999(97)00132-3

Bächtold, D., Baumann, T., Sándor, P. S., Kritos, M., Regard, M., and Brugger, P. (2001). Spatial- and verbal-memory improvement by cold-water caloric stimulation in healthy subjects. Exp. Brain Res. 136, 128-132. doi: 10.1007/s002210000588

Baek, J.-H., Zheng, Y., Darlington, C. L., and Smith, P. F. (2010). Evidence that spatial memory deficits in rats following bilateral vestibular loss is probably permanent. Neurobiol. Learn. Mem. 94, 402-413. doi: 10.1016/j.nlm.2010.08.007

Balaban, C. D. (2002). Neural substrates linking balance control and anxiety. Physiol. Behav. 77, 469-475. doi: 10.1016/S0031-9384(02)00935-6

Balaban, C. D., and Thayer, J. F. (2001). Neurological bases for balance-anxiety links. J. Anxiety Disord. 15, 53-79. doi: 10.1016/S0887-6185(00)00042-6

Bannerman, D. M., Deacon, R. M., Offen, S., Friswell, J., Grubb, M., and Rawlins, J. N. (2002). Double dissociation of function within the hippocampus: spatial memory and hyponeophagia. Behav. Neurosci. 116, 884-901. doi: 10.1037/07357044.116.5.884

Bannerman, D. M., Rawlins, J. N., McHugh, S. B., Deacon, R. M., Yee, B. K., Bast, T., et al. (2004). Regional dissociations within the hippocampus-memory and anxiety. Neurosci. Biobehav. Rev. 28, 273-283. doi: 10.1016/j.neubiorev.2004.03.004

Bannerman, D. M., Yee, B. K., Good, M. A., Heupel, M. J., Iversen, S. D., and Rawlins, J. N. (1999). Double dissociation of function within the hippocampus: a comparison of dorsal, ventral, and complete hippocampal cytotoxic lesions. Behav. Neurosci. 113, 1170-1188. doi: 10.1037/0735-7044.113.6.1170

Bense, S., Stephan, T., Yousry, T. A., Brandt, T., and Dieterich, M. (2001). Multisensory cortical signal increases and decreases during vestibular galvanic stimulation (fMRI). J. Neurophysiol. 85, 886-899.

Beritoff, J. S. (1965). Neural Mechanisms of Higher Vertebrates. Boston, MA: Little, Brown and Co.

Berthoz, A. (1996). "How does the cerebral cortex process and utilize vestibular signals," in Disorders of the Vestibular System, eds R. Baloh and G. M. Halmagyi (New York-Oxford: Oxford University Press), 113-125.

Besnard, S., Machado, M. L., Vignaux, G., Boulouard, M., Coquerel, A., Bouet, V., et al. (2012). Influence of vestibular input on spatial and nonspatial memory and on hippocampal NMDA receptors. Hippocampus 22, 814-826. doi: 10.1002/hipo.20942

Best, C., Eckhardt-Henn, A., Diener, G., Bense, S., Breuer, P., and Dieterich, M. (2006). Interaction of somatoform and vestibular disorders. J. Neurol. Neurosurg. Psychiatry 77, 658-664. doi: 10.1136/jnnp.2005.072934

Black, F. O., Pesznecker, S., and Stallings, V. (2004). Permanent gentamicin vestibulotoxicity. Otol. Neurotol. 25, 559-569. doi: 10.1097/00129492-20040700000025

Bolmont, B., Gangloff, P., Vouriot, A., and Perrin, P. P. (2002). Mood states and anxiety influence abilities to maintain balance control in healthy human subjects. Neurosci. Lett. 329, 96-100. doi: 10.1016/S0304-3940(02)00578-5

Borel, L., Harlay, F., Loopez, C., Magnan, J., Chays, A., and Lacour, M. (2004). Walking performance in vestibular-defective patients before and after unilateral vestibular neurrectomy. Behav. Brain Res. 150, 191-200. doi: 10.1016/S01664328(03)00257-2

Brandt, T., Schautzer, F., Hamilton, D. A., Bruning, R., Markowitsch, H., Kalla, R., et al. (2005). Vestibular loss causes hippocampal atrophy and impaired spatial memory in humans. Brain 128, 2732-2741. doi: 10.1093/brain/ awh617

Brown, J. E., Yates, B. J., and Taube, J. S. (2002). Does the vestibular system contribute to head direction cell activity in the rat. Physiol. Behav. 77, 743-748. doi: 10.1016/S0031-9384(02)00928-9

Calton, J. L., and Taube, J. S. (2005). Degradation of head direction cell activity during inverted locomotion. J. Neurosci. 25, 2420-2428. doi: 10.1523/JNEUROSCI.3511-04.2005

Chapuis, N., Krimm, M., de Waele, C., Vibert, N., and Berthoz, A. (1992). Effect of post-training unilateral labyrinthectomy in a spatial orientation task by guinea pigs. Behav. Brain Res. 51, 115-126. doi: 10.1016/S0166-4328(05) 80205-0

Chen, A., Deangelis, G. C., and Angelaki, D. E. (2013). Functional specializations of the ventral intraparietal area for multisensory heading discrimination. J. Neurosci. 33, 3567-3581. doi: 10.1523/JNEUROSCI.4522-12.2013

Cohen, H. S. (2000). Vestibular disorders and impaired path integration along a linear trajectory. J. Vestib. Res. 10, 7-15.
Cohen, H. S., and Kimball, K. T. (2002). Improvements in path integration after vestibular rehabilitation. J. Vestib. Res. 12, 47-51.

Curthoys, I. S., and Halmagyi, G. M. (1995). Vestibular compensation: a review of the ocular motor, neural and clinical consequences of unilateral vestibular loss. J. Vestib. Res. 5, 67-107. doi: 10.1016/0957-4271(94)00026-X

Cuthbert, P. C., Gilchrist, D. P., Hicks, S. L., MacDougall, H. G., and Curthoys, I. S. (2000). Electrophysiological evidence for vestibular activation of the guinea pig hippocampus. Neuroreport 11, 1443-1447. doi: 10.1097/00001756-20000515000018

De Waele, C., Baudonniere, P. M., Lepecq, J. C., Tran Ba Huy, P., and Vidal, P. P. (2001). Vestibular projections in the human cortex. Exp. Brain Res. 141, 541-551. doi: 10.1007/s00221-001-0894-7

Dilda, V., MacDougall, H. G., Curthoys, I. S., and Moore, S. T. (2012). Effects of galvanic vestibular stimulation on cognitive function. Exp. Brain Res. 216, 275-285. doi: 10.1007/s00221-011-2929-z

Eagger, S., Luxon, L. M., Davies, R. A., Coelho, A., and Ron, M. A. (1992). Psychiatric morbidity in patients with peripheral vestibular disorder: a clinical and neuro-otological study. J. Neurol. Neurosurg. Psychiatry 55, 383-387. doi: 10.1136/jnnp. 55.5 .383

Etienne, A. S. (1980). The orientation of the golden hamster to its nest-site after the elimination of various sensory cues. Experientia 36, 1048-1050. doi: 10.1007/BF01965961

Etienne, A. S., and Jeffery, K. (2004). Path integration in mammals. Hippocampus 14, 180-192. doi: 10.1002/hipo.10173

Falconer, C. J., and Mast, F. W. (2012). Balancing the mind. Vestibular-induced facilitation of egocentric transformations. Exp. Psychol. 59, 332-339. doi: 10.1027/1618-3169/a000161

Furman, J. M., and Jacob, R. G. (2001). A clinical taxonomy of dizziness and anxiety in the otoneurological setting. J. Anxiety Disord. 15, 9-26. doi: 10.1016/S08876185(00)00040-2

Furman, J. M., Redfern, M. S., and Jacob, R. G. (2006). Vestibulo-ocular function in anxiety disorders. J. Vestib. Res. 16, 209-215.

Gavrilov, V. V., Wiener, S. I., and Berthoz, A. (1995). Enhanced hippocampal theta EEG during whole body rotations in awake restrained rats. Neurosci. Lett. 197, 239-241. doi: 10.1016/0304-3940(95)11918-M

Giocomo, L. M., Moser, M. B., and Moser, E. I. (2011). Computational models of grid cells. Neuron 71, 589-603. doi: 10.1016/j.neuron.2011.07.023

Gizzi, M., Zlotnick, M., Cicerone, K., and Riley, E. (2003). Vestibular disease and cognitive dysfunction: no evidence for a causal connection. J. Head Trauma Rehabil. 18, 398-407. doi: 10.1097/00001199-200309000-00002

Goble, T. J., Møller, A. R., and Thompson, L. T. (2009). Acute high-intensity sound exposure alters responses of place cells in hippocampus. Hear Res. 253, 52-59. doi: 10.1016/j.heares.2009.03.002

Goddard, M., Zheng, Y., Darlington, C. L., and Smith, P. F. (2008). Locomotor and exploratory behaviour in the rat following bilateral vestibular deafferentation. Behav. Neurosci. 122, 448-459. doi: 10.1037/0735-7044.122.2.448

Godemann, F., Koffroth, C., Neu, P., and Heuser, I. (2004a). Why does vertigo become chronic after neuropathia vestibularis. Psychosom. Med. 66, 783-787. doi: 10.1097/01.psy.0000140004.06247.c9

Godemann, F., Linden, M., Neu, P., Heipp, E., and Dörr, P. (2004b). A prospective study on the course of anxiety after vestibular neuronitis. J. Psychosom. Res. 56, 351-354. doi: 10.1016/S0022-3999(03)00079-5

Godemann, F., Schuller, J., Uhlemann, H., Budde, A., Heinz, A., Ströhle, A., et al. (2009). Psychodynamic vulnerability factors in the development of panic disorders-a prospective trial in patients after vestibular neuritis. Psychopathology 42, 99-107. doi: 10.1159/000203342

Grabherr, L., Cuffel, C., Guyot, J. P., and Mast, F. W. (2011). Mental transformation abilities in patients with unilateral and bilateral vestibular loss. Exp. Brain Res. 209, 205-214. doi: 10.1007/s00221-011-2535-0

Gray, J. A., and McNaughton, N. (2003). The Neuropsychology of Anxiety. An Enquiry into the Function of the Sept-Hippocampal System. 2nd Edn., Oxford: Oxford University Press. doi: 10.1093/acprof:oso/9780198522713.001.0001

Grimm, R. J., Hemenway, W. G., Lebray, P. R., and Black, F. O. (1989). The perilymph fistula syndrome defined in mild head trauma. Acta Otolaryngol. Suppl. 464, 1-40. doi: 10.3109/00016488909138632

Grunfeld, E. A., Gresty, M. A., Bronstein, A. M., and Jahanshahi, M. (2003). Screening for depression among neuro-otology patients with and without identifiable vestibular lesions. Int. J. Audiol. 42, 161-165. doi: $10.3109 / 14992020309090425$ 
Guidetti, G., Monzani, D., Trebbi, M., and Rovatti, V. (2008). Impaired navigation skills with psychological distress and chronic peripheral vestibular hypofunction without vertigo. Arch. Otorhinolarngol. Ital. 28, 21-25.

Guldin, W. O., and Grusser, O. J. (1998). Is there a vestibular cortex. Trends Neurosci. 21, 254-259. doi: 10.1016/S0166-2236(97)01211-3

Gurvich, C., Maller, J. J., Lithgow, B., Haghgooie, S., and Kulkarni, J. (2013). Vestibular insights into cognition and psychiatry. Brain Res. 1537, 244-259. doi: 10.1016/j.brainres.2013.08.058

Gu, Y., DeAngelis, G. C., and Angelaki, D. E. (2007). A functional link between area MSTd and heading perception based on vestibular signals. Nat. Neurosci. 10, 1038-1047. doi: 10.1038/nn1935

Halberstadt, A. L., and Balaban, C. D. (2006). Serotonergic and nonserotonergic neurons in the dorsal raphe nucleus send collateralized projections to both the vestibular nuclei and the central amygdaloid nucleus. Neuroscience 140, 1067-1077. doi: 10.1016/j.neuroscience.2006.02.053

Hanes, D. A., and McCollum, G. (2006). Cognitive-vestibular interactions: a review of patient difficulties and possible mechanisms. J. Vestib. Res. 16, 75-91.

Hasselmo, M. E. (2005). What is the function of hippocampal theta rhythm. Linking behavioural data to phasic properties of field potential and unit recording data. Hippocampus 15, 936-949. doi: 10.1002/hipo.20116

Helmchen, C., Ye, Z., Sprenger, A., and Münte, T. F. (2013). Changes in resting-state fMRI in vestibular neuritis. Brain Struct. Funct. doi: 10.1007/s00429-013-06085. [Epub ahead of print].

Horii, A., Russell, N., Smith, P. F., Darlington, C. L., and Bilkey, D. K. (2004). Vestibular influences on CA1 neurons in the rat hippocampus: an electrophysiological study in vivo. Exp. Brain Res. 155, 245-250. doi: 10.1007/s00221-0031725-9

Horii, A., Takeda, N., Mochizuki, T., Okakura-Mochizuki, K., Yamamoto, Y., and Yamatodani, A. (1994). Effects of vestibular stimulation on acetylcholine release from rat hippocampus: an in vivo microdialysis study. J. Neurophysiol. 72, 605-611.

Horii, A., Uno, A., Kitahara, T., Mitani, K., Masumura, C., Kizawa, K., et al. (2007). Effects of fluvoxamine on anxiety, depression and subjective handicaps of chronic dizziness patients with or without neuro-otologic diseases. J. Vestib. Res. 17, 1-8.

Horn, K. M., DeWitt, J. R., and Nielson, H. C. (1981). Behavioral assessment of sodium arsanilate induced vestibular dysfunction in rats. Physiol. Psych. 9, 371-378. doi: 10.3758/BF03326998

Hüfner, K., Binetti, C., Hamilton, D. A., Stephan, T., Flanagin, V. L., Linn, J., et al. (2010). Structural and functional plasticity of the hippocampal formation in professional dancers and slackliners. Hippocampus 21, 855-865. doi: 10.1002/hipo.20801

Hüfner, K., Stephan, T., Hamilton, D. A., Kalla, R., Glasauer, S., Strupp, M., et al. (2009) Gray-matter atrophy after chronic complete unilateral vestibular deafferentation. Ann. N. Y. Acad. Sci. 1164, 383-385. doi: 10.1111/j.17496632.2008.03719.

Hüfner, K., Hamilton, D. A., Kalla, R., Stephan, T., Glasauer, S., Ma, J., et al. (2007) Spatial memory and hippocampal volume in humans with unilateral vestibular deafferentation. Hippocampus. 17, 471-485. doi: 10.1002/hipo.20283

Hufner, K., Strupp, M., Brandt, T., Smith, P. F., and Jahn, K. (2011). Spatial separation of visual and vestibular processing in the human hippocampus. Ann. N.Y. Acad. Sci. 1233, 177-186. doi: 10.1111/j.1749-6632.2011.06115.x

Jauregui-Renaud, K., Ramos-Toledo, V., Aguilar-Bolanos, M., Montano-Velazquez, B., and Pliego-Maldonado, A. (2008a). Symptoms of detachment from the self or from the environment in patients with an acquired deficiency of the special senses. J. Vestib. Res. 18, 129-137.

Jauregui-Renaud, K., Sang, F. Y., Gresty, M. A., Green, D. A., and Bronstein, A. M. (2008b). Depersonalisation/derealisation symptoms and updating orientation in patients with vestibular disease. J. Neurol. Neurosurg. Psychiatry 79, 276-283. doi: 10.1136/jnnp.2007.122119

Jeewajee, A., Barry, C., O'Keefe, J., and Burgess, N. (2008). Grid cells and theta as oscillatory interference: electrophysiological data from freely moving rats. Hippocampus 18, 1175-1185. doi: 10.1002/hipo.20510

Karnath, H.-O., and Dieterich, M. (2006). Spatial neglect-a vestibular disorder. Brain 129, 293-305. doi: 10.1093/brain/awh698

Kim, D. J., Yogendrakumar, V., Chiang, J., Ty, E., Wang, Z. J., and McKeown, M. J. (2013). Noisy galvanic vestibular stimulation modulates the amplitude of EEG synchrony patterns. PLoS ONE 8:e69055. doi: 10.1371/journal.pone.0069055
Lever, C., Jeewajee, A., Burton, S., O'Keefe, J., and Burgess, N. (2009). Hippocampal theta frequency, novelty and behavior. Hippocampus 19, 409-410. doi: 10.1002/hipo. 20557

Lobel, E., Kleine, J. F., Bihan, D. L., Leroy-Willig, A., and Berthoz, A. (1998). Functional MRI of galvanic vestibular stimulation. J. Neurophysiol. 80, 2699-2709.

Lopez, C., and Blanke, O. (2011). The thalamocortical vestibular system in animals and humans. Brain Res Rev. 67, 119-146. doi: 10.1016/j.brainresrev.2010.12.002

Machado, M. L., Kroichvili, N., Freret, T., Philoxène, B., Lelong-Boulouard, V., Denise, P., et al. (2012a). Spatial and non-spatial performance in mutant mice devoid of otoliths. Neurosci. Lett. 522, 57-61. doi: 10.1016/j.neulet.2012. 06.016

Machado, M. L., Lelong-Boulouard, V., Smith, P. F., Freret, T., Philoxene, B., Denise, P., et al. (2012b). Influence of anxiety in spatial memory impairments related to the loss of vestibular function in rat. Neuroscience 218, 161-169. doi: 10.1016/j.neuroscience.2012.05.029

Mathews, B. L., Campbell, K. A., and Deadwyler, S. A. (1988). Rotational stimulation disrupts spatial learning in fornix-lesioned rats. Behav. Neurosci. 102, 35-42. doi: 10.1037/0735-7044.102.1.35

Mathews, B. L., Ryu, J. H., and Bockaneck, C. (1989). Vestibular contribution to spatial orientation. Evidence of vestibular navigation in an animal model. Acta Otolaryngol. Suppl. 468, 149-154. doi: 10.3109/00016488909139036

McNaughton, B. L., Barnes, C. A., Gerard, J. L., Gothard, K., Jung, M. W., Knierim, J. J., et al. (1996). Deciphering the hippocampal polyglot: the hippocampus as a path integration system. J. Exp. Biol. 199, 173-185.

McNaughton, B. L., Battaglia, F. P., Jensen, O., Moser, E. I., and Moser, M. B. (2006). Path integration and the neural basis of the 'cognitive map'. Nat. Rev. Neurosci. 7, 663-678. doi: 10.1038/nrn1932

Miller, S. M., Potegal, L., and Abraham, L. (1983). Vestibular involvement in a passive transport and return task. Physiol. Psychol. 11, 1-10. doi: 10.3758/BF03326763

Mittelstaedt, M. L., and Mittelstaedt, H. (1980). Homing by path integration in a mammal. Naturewissenschaften 67, 556-567. doi: 10.1007/ BF00450672

Monzani, D., Casolari, L., Guidetti, G., and Rigatelli, M. (2001). Psychological distress and disability in patients with vertigo. J. Psychosom. Res. 50, 319-323. doi: 10.1016/S0022-3999(01)00208-2

Moss, F., Ward, L. M., and Sannita, W. G. (2004). Stochastic resonance and sensory information processing: a tutorial and review of application. Clin. Neurophysiol. 115, 267-281. doi: 10.1016/j.clinph.2003.09.014

Muir, G. M., Brown, J. E., Carey, J. P., Hirvonen, T. P., Della Santina, C. C., Minor, L. B., et al. (2009). Disruption of the head direction cell signal after occlusion of the semicircular canals in the freely moving chinchilla. J. Neurosci. 29, 14521-14533. doi: 10.1523/JNEUROSCI.3450-09.2009

Neo, P., Carter, D., Zheng, Y., Smith, P. F., Darlington, C. L., and McNaughton, N. (2012). Septal elicitation of hippocampal theta rhythm did not repair the cognitive and emotional deficits resulting from vestibular lesions. Hippocampus 22, 1176-1187. doi: 10.1002/hipo.20963

Ossenkopp, K. P., and Hargreaves, E. L. (1993). Spatial learning in an enclosed eight-arm maze in rats with sodium arsinilate-induced labyrinthectomies. Behav. Neural Biol. 59, 253-257. doi: 10.1016/0163-1047(93) 91034-K

Persoons, P., Luyckx, K., Desloovere, C., Vandenberghe, J., and Fischler, B. (2003). Anxiety and mood disorders in otorhinolaryngology outpatients presenting with dizziness: validation of the self-administered PRIME-MD Patient Health Questionnaire and epidemiology. Gen. Hosp. Psychiatry 25, 316-323. doi: 10.1016/S0163-8343(03)00072-0

Peruch, P., Borel, L., Gaunet, F. Thinus-Blanc, G., Magnan, J., and Lacour, M. (1999). Spatial performance of unilateral vestibular defective patients in nonvisual versus visual navigation. J. Vestib. Res. 9, 37-47.

Péruch, P., Lopez, C., Redon-Zouiteni, C., Escoffier, G., Zeitoun, A., Sanjuan, M., et al. (2011). Vestibular information is necessary for maintaining metric properties of representational space: evidence from mental imagery. Neuropsychologia 49, 3136-3144. doi: 10.1016/j.neuropsychologia. 2011.07.026

Petrosini, L. (1984). Task-dependent rate of recovery from hemilabyrinthectomy: an analysis of swimming and locomotor performances. Physiol. Behav. 33, 799-804. doi: 10.1016/0031-9384(84)90050-7 
Pollak, L., Klein, C., Rafael, S., Vera, K., and Rabey, J. M. (2003). Anxiety in the first attack of vertigo. Otolaryngol. Head Neck Surg. 128, 829-834. doi: 10.1016/S0194-5998(03)00454-6

Potegal, M. (1982). "Vestibular and neostriatal contributions to spatial orientation," in Spatial Abilities: Development and Physiological Foundation. ed M. Potegal (New York, NY: Academic Press), 361-387.

Potegal, M., Day, M. J., and Abraham, L. (1977). Maze orientation, visual and vestibular cues in two-maze spontaneous alternation of rats. Physiol. Psychol. 5, 414-420.

Redfern, M. S., Talkowski, M. E., Jennings, J. R., and Furman, J. M. (2004). Cognitive influences in postural control of patients with unilateral vestibular loss. Gait Posture. 19, 105-114. doi: 10.1016/S0966-6362(03) 00032-8

Risey, J., and Briner, W. (1990-1991). Dyscalculia in patients with vertigo. J. Vestib. Res. 1, 31-37.

Russell, N., Horii, A., Smith, P. F., Darlington, C. L., and Bilkey, D. (2003a). Effects of bilateral vestibular deafferentation on radial arm maze performance. J. Vestib. Res 13, 9-16.

Russell, N., Horii, A., Smith, P. F., Darlington, C. L., and Bilkey, D. (2003b). The long-term effects of permanent vestibular lesions on hippocampal spatial firing. J. Neurosci. 23, 6490-6498.

Russell, N., Horii, A., Smith, P. F., Darlington, C. L., and Bilkey, D. (2006). Lesions of the vestibular system disrupt hippocampal theta rhythm in the rat. J. Neurophysiol. 96, 4-14. doi: 10.1152/jn.00953.2005

Saber Tehrani, A. S., Coughlan, D., Hsieh, Y. H., Mantokoudis, G., Korley, F. K., Kerber, K. A., et al. (2013). Rising annual costs of dizziness presentations to u.s. Emergency departments. Acad. Emerg. Med. 20, 689-696. doi: 10.1111/acem. 12168

Sakurai, Y. (1990). Hippocampal cells have behavioral correlates during the performance of an auditory working memory task in the rat. Behav. Neurosci. 104, 253-263. doi: 10.1037/0735-7044.104.2.253

Sakurai, Y. (1994). Involvement of auditory cortical and hippocampal neurons in auditory working memory and reference memory in the rat. J. Neurosci. 14, 2606-2623.

Sang, F. Y., Jáuregui-Renaud, K., Green, D. A., Bronstein, A. M., and Gresty, M. A. (2006). Depersonalisation/derealisation symptoms in vestibular disease. J. Neurol. Neurosurg. Psychiatry 77, 760-766. doi: 10.1136/jnnp.2005. 075473

Schaeppi, U., Krinke, G., FitzGerald, R. E., and Classen, W. (1991). Impaired tunnel-maze behavior in rats with sensory lesions: vestibular and auditory systems. Neurotoxicology 12, 445-454.

Schautzer, F., Hamilton, D., Kalla, R., Strupp, M., and Brandt, T. (2003). Spatial memory deficits in patients with chronic bilateral vestibular failure. Ann. N.Y. Acad. Sci. 1004, 316-324. doi: 10.1196/annals.1303.029

Semenov, L. V., and Bures, J. (1989). Vestibular stimulation disrupts acquisition of place navigation in the Morris water tank task. Behav. Neural Biol. 51, 346-363. doi: 10.1016/S0163-1047(89)90987-4

Shinder, M. E., and Taube, J. S. (2010). Differentiating ascending vestibular pathways to the cortex involved in spatial cognition. J. Vestib. Res. 20, 3-23.

Simon, N. M., Parker, S. W., Wernick-Robinson, M., Oppenheimer, J. E., Hoge, E. A., Worthington, J. J., et al. (2005). Fluoxetine for vestibular dysfunction and anxiety: a prospective pilot study. Psychosomatics 46, 334-339. doi: 10.1176/appi.psy.46.4.334

Smith, P. F. (1997). Vestibular-hippocampal interactions. Hippocampus 7, 465-471. doi: 10.1002/(SICI) 1098-1063(1997)7:5<465::AID-HIPO3 > 3.0.CO;2-G

Smith, P. F. (2012). Dyscalculia and vestibular function. Med. Hypoth. 79, 493-496. doi: 10.1016/j.mehy.2012.06.032

Smith, P. F., Brandt, T., Strupp, M., Darlington, C. L., and Zheng, Y. (2009). Balance before reason in rats and humans. Ann. N.Y. Acad. Sci. 1164, 127-133. doi: 10.1111/j.1749-6632.2008.03726.x

Smith, P. F., and Curthoys, I. S. (1989). Mechanisms of recovery following peripheral vestibular lesions: a review. Brain Res. Rev. 14, 155-180. doi: 10.1016/01650173(89)90013-1

Smith, P. F., Darlington, C. L., and Zheng, Y. (2010). Move it or lose it: is stimulation of the vestibular system necessary for normal spatial memory. Hippocampus 20, 36-43. doi: 10.1002/(SICI) 1098-1063(1997)7:5<465::AID-HIPO3>3. $0 . \mathrm{CO} ; 2-\mathrm{G}$

Smith, P. F., Haslett, S. J., and Zheng, Y. (2013). A multivariate statistical and data mining analysis of spatial memory-related behaviour following bilateral vestibular deafferentation in the rat. Behav. Brain Res. 246, 15-23. doi: 10.1016/j.bbr.2013.02.033

Smith, P. F., Horii, A., Russell, N., Bilkey, D., Zheng, Y., Liu, P., et al. (2005a). The effects of vestibular damage on hippocampal function in rats. Prog. Neurobiol. 75, 391-405. doi: 10.1016/j.pneurobio.2005.04.004

Smith, P. F., Zheng, Y., Horii, A., and Darlington, C. L. (2005b). Does vestibular damage cause cognitive dysfunction in humans. J. Vestib. Res. 15, 1-9.

Smith, P. F., and Zheng, Y. (2013). Principal component analysis suggests subtle changes in glutamate receptor subunit expression in the rat hippocampus following bilateral vestibular deafferentation in the rat. Neurosci. Lett. 548, 265-268. doi: 10.1016/j.neulet.2013.05.036

Staab, J. P. (2006). Chronic dizziness: the interface between psychiatry and neuro-otology. Curr. Opin. Neurol. 19, 41-48. doi: 10.1097/01.wco.0000198102.95294.1f

Staab, J. P., and Ruckenstein, M. J. (2003). Which comes first? Psychogenic dizziness versus otogenic anxiety. Laryngoscope. 113, 1714-1718. doi: 10.1097/00005537200310000-00010

Staab, J. P., Ruckenstein, M. J., Solomon, D., and Shepard, N. T. (2002). Serotonin reuptake inhibitors for dizziness with psychiatric symptoms. Arch. Otolaryngol. Head Neck Surg. 128, 554-560. doi: 10.1001/archotol.128.5.554

Stackman, R. W., Clark, A. S., and Taube, J. S. (2002). Hippocampal spatial representations require vestibular input. Hippocampus 12, 291-303. doi: 10.1002/hipo.1112

Stackman, R. W., and Herbert, A. M. (2002). Rats with lesions of the vestibular system require a visual landmark for spatial navigation. Behav. Brain Res. 128, 27-40. doi: 10.1016/S0166-4328(01)00270-4

Stackman, R. W., and Taube, J. S. (1997). Firing properties of head direction cells in the rat anterior thalamic nucleus: dependence on vestibular input. J. Neurosci. 17, 4349-4358.

Stiles, L., Zheng, Y., Darlington, C. L., and Smith, P. F. (2012). The D2 dopamine receptor and locomotor hyperactivity following bilateral vestibular deafferentation in the rat. Behav. Brain Res. 227, 150-158. doi: 10.1016/j.bbr.2011.11.006

Tai, S. K., Ma, J., Ossenkopp, K. P., and Leung, L. S. (2012). Activation of immobility-related hippocampal theta by cholinergic septohippocampal neurons during vestibular stimulation. Hippocampus 22, 914-925. doi: 10.1002/hipo.20955

Talkowski, M. E., Redfern, M. S., Jennings, J. R., and Furman, J. M. (2005). Cognitive requirements for vestibular and ocular motor processing in healthy adults and patients with unilateral vestibular lesions. J. Cogn. Neurosci. 17, 1432-1441. doi: 10.1162/0898929054985419

Tecer, A., Tükel, R., Erdamar, B., and Sunay, T. (2004). Audiovestibular functioning in patients with panic disorder. J. Psychosom. Res. 57, 177-182. doi: 10.1016/S0022-3999(03)00568-3

Venault, P., Rudrauf, D., Lepicard, E. M., Berthoz, A., Jouvent, R., and Chapouthier, G. (2001). Balance control and posture in anxious mice improved by SSRI treatment. NeuroReport 12, 3091-3094. doi: 10.1097/00001756-200110080-00022

Vertes, R. P. (2005). Hippocampal theta rhythm: a tag for short-term memory. Hippocampus 15, 923-935. doi: 10.1002/hipo.20118

Vitte, E., Derosier, C., Caritu, Y., Berthoz, A., Hasboun, D., and Soulie, D. (1996). Activation of the hippocampal formation by vestibular stimulation: a functional magnetic resonance imaging study. Exp. Brain Res. 112, 523-526. doi: 10.1007/BF00227958

Wallace, D. G., Hines, D. J., Pellis, S. M., and Whishaw, I. Q. (2002). Vestibular information is required for dead reckoning in the rat. J. Neurosci. 22, 10009-10017.

Wiener, S. I., and Berthoz, A. (1993). "Forebrain structures mediating the vestibular contribution during navigation," in Multisensory Control of Movement, ed A. Berthoz (Oxford: Oxford University Press), 427-456. doi: 10.1093/acprof:oso/9780198547853.003.0208

Wiener, S. I., Korshunov, V. A., Garcia, R., and Berthoz, A. (1995). Inertial, substratal and landmark cue control of hippocampal CA1 place cell activity. Eur. J. Neurosci. 7, 2206-2219. doi: 10.1111/j.1460-9568.1995.tb00642.x

Wilkinson, D., Ferguson, H. J., and Worley, A. (2012). Galvanic vestibular stimulation modulates the electrophysiological response during face processing. Vis. Neurosci. 29, 255-262. doi: 10.1017/S0952523812000235

Wilkinson, D., Ko, P., Kilduff, P., McGlinchey, R., and Milberg, W. (2005). Improvement of a face perception deficit via subsensory galvanic vestibular stimulation. J. Int. Neuropsychol. Soc. 11, 925-929. doi: $10.1017 /$ S1355617705051076 
Wilkinson, D., Nicholls, S., Pattenden, C., Kilduff, P., and Milberg, W. (2008). Galvanic vestibular stimulation speeds visual memory recall. Exp. Brain Res. 189, 243-248. doi: 10.1007/s00221-008-1463-0

Wilkinson, D., Zubko, O., DeGutis, J., Milberg, W., and Potter, J. (2010). Improvement of a figure copying deficit during subsensory galvanic vestibular stimulation. J. Neuropsychol. 4, 107-118. doi: 10.1348/174866409X468205

Yardley, L., Gardner, M., Bronstein, A., Davies, R., Buckwell, D., and Luxon, L. (2001). Interference between postural control and mental task performance in patients with vestibular disorders and healthy controls. J. Neurol. Neurosurg. Psychiatry 71, 48-542. doi: 10.1136/jnnp.71.1.48

Yardley, L., Papo, D., Bronstein, A., Gresty, M., Gardner, M., Lavie, N., et al. (2002). Attentional demands of continuously monitoring orientation using vestibular information. Neuropsychologia 40, 373-383. doi: 10.1016/S00283932(01)00113-0

Yoder, R. M., and Taube, J. S. (2009). Head direction cell activity in mice: robust directional signal depends on intact otolith organs. J. Neurosci. 29, 1061-1076. doi: 10.1523/JNEUROSCI.1679-08.2009

Zheng, Y., Balabhadrapatruni, S., Chung, P., Gliddon, C. M., Zhang, M., et al. (2012a). The effects of bilateral vestibular loss on hippocampal volume, neuronal number and cell proliferation in rats. Front. Neurol. 3, 1-8. doi: 10.3389/fneur.2012.00020

Zheng, Y., Cheung, I., and Smith, P. F. (2012b). Performance in anxiety and spatial memory tests following bilateral vestibular loss in the rat and effects of anxiolytic and anxiogenic drugs. Behav. Brain Res. 235, 21-29. doi: 10.1016/j.bbr.2012.07.025

Zheng, Y., Balabhadrapatruni, S., Munn, O., Masumura, C., Darlington, C. L., and Smith, P. F. (2009a). Evidence for deficits in a 5 choice serial reaction time task in rats with bilateral vestibular deafferentation. Behav. Brain Res. 203, 113-117. doi: 10.1016/j.bbr.2009.04.027

Zheng, Y., Goddard, M., Darlington, C. L., and Smith, P. F. (2009b). Long-term deficits on a foraging task after bilateral vestibular deafferentation in rats. Hippocampus 19, 480-486. doi: 10.1002/hipo.20533

Zheng, Y., Goddard, M., Darlington, C. L., and Smith, P. F. (2008). The effects of bilateral vestibular deafferentation on anxiety-related behaviours in Wistar rats. Behav. Brain Res. 193, 55-62. doi: 10.1016/j.bbr.2008.04.018.

Zheng, Y., Darlington, C. L., and Smith, P. F. (2004). Bilateral vestibular deafferentation impairs object recognition in rat. Neuroreport 15, 1913-1916. doi: 10.1097/00001756-200408260-00016

Zheng, Y., Darlington, C. L., and Smith, P. F. (2006). Impairment and recovery on a food foraging task following unilateral vestibular deafferentation in rat. Hippocampus 16, 368-378. doi: 10.1002/hipo.20149

Zheng, Y., Goddard, M., Darlington, C. L., and Smith, P. F. (2007). Bilateral vestibular deafferentation impairs performance in a spatial forced alternation task in rats. Hippocampus 17, 253-256. doi: 10.1002/hipo.20266
Zheng, Y., Hamilton, E., Begum, S., Smith, P. F., and Darlington, C. L. (2011). The effects of acoustic trauma that can cause tinnitus on spatial performance in rats. Neuroscience 186, 48-56. doi: 10.1016/j.neuroscience.2011.04.052

Zheng, Y., Pearce, J. M., Vann, S. D., Good, M., Trish, A., Smith, P. F., et al. (2003). Using idiothetic cues to learn a swim path with a fixed trajectory and distance: Involvement of the hippocampus but not the retrosplenial cortex. Behav. Neurosci. 117, 1363-1377. doi: 10.1037/07357044.117.6.1363

Zheng, Y., Wilson, G., Stiles, L., and Smith, P. F. (2013). Glutamate receptor subunit and calmodulin kinase II expression in the rat hippocampus, with and without $\mathrm{T}$ maze experience, following bilateral vestibular deafferentation. PLOS ONE 8:e54527. doi: 10.1371/journal.pone. 0054527

Zou, D., Aitake, M., Hori, E., Umeno, K., Fukuda, M., Ono, T., et al. (2009). Rat hippocampal theta rhythm during sensory mismatch. Hippocampus 19, 350-359. doi: 10.1002/hipo.20524

Zubko, O., Wilkinson, D., Langston, D., and Sakel, M. (2013). The effect of repeated sessions of galvanic vestibular stimulation on target cancellation in visuo-spatial neglect: preliminary evidence from two cases. Brain Inj. 27, 613-619. doi: 10.3109/02699052. 2013.767938

zu Eulenburg, P., Stoeter, P., and Dieterich, M. (2010). Voxel-based morphometry depicts central compensation after vestibular neuritis. Ann. Neurol. 68, 241-249. doi: 10.1002/ana.22063

Conflict of Interest Statement: The authors declare that the research was conducted in the absence of any commercial or financial relationships that could be construed as a potential conflict of interest.

Received: 01 August 2013; paper pending published: 13 September 2013; accepted: 07 November 2013; published online: 26 November 2013.

Citation: Smith PF and Zheng Y (2013) From ear to uncertainty: vestibular contributions to cognitive function. Front. Integr. Neurosci. 7:84. doi: 10.3389/fnint. 2013.00084

This article was submitted to the journal Frontiers in Integrative Neuroscience. Copyright (c) 2013 Smith and Zheng. This is an open-access article distributed under the terms of the Creative Commons Attribution License (CC BY). The use, distribution or reproduction in other forums is permitted, provided the original author(s) or licensor are credited and that the original publication in this journal is cited, in accordance with accepted academic practice. No use, distribution or reproduction is permitted which does not comply with these terms. 